\title{
El manual como texto
}

\author{
Agustín Escolano Benito*
}

\section{Resumen}

Este trabajo aborda la cuestión de la identidad del libro escolar como un género textual específico en el contexto de la manualística clásica y moderna, contextualizando los análisis en el marco de la cultura de la escuela tradicional y en la era de la revolución

* Centro Internacional de la Cultura Escolar, Universidad de Valladolid, España. agustin@ceince.eu digital y bajo una perspectiva historiográfica y teórica. También plantea el nacimiento y primeros desarrollos de la manualística como campo intelectual y académico y sus contribuciones a la definición de la identidad del libro escolar.

\section{Palabras clave}

manual escolar; género textual; manualística; cultura de la escuela; hipertexto; giro digital. 


\begin{abstract}
This paper discusses the question of identifying a coursebook as a specific text genre in the context of the classical and modern manualistics, situating the analysis within the traditional school culture and the digital revolution era, under a historical and theoretical perspective. It also covers the birth and initial development of manualistics as an intelectual and academic field and its contributions to the definition of the schoolbook identity.
\end{abstract}

Key words schoolbook, text genre; manualistics; school culture; hypertext; digital era. 


\section{El manual, un texto con identidad}

El libro escolar es, en efecto, una clase específica de texto que se materializa en su forma impresa o en las escrituras relacionales de la red. Hoy nadie confunde un manual, ya sea en copia sobre papel o en pantalla, con otro tipo de texto. Puede afirmarse que el libro escolar es un género textual con atributos propios reconocido así por los sujetos que lo utilizan y por la sociedad en que circula como objeto. Además, sobre todo a partir de las últimas décadas, los académicos hemos asignado un estatuto especial al texto escolar como fuente de conocimiento para el estudio de la cultura de la escuela y los modos de sociabilidad de los menores en las instituciones de formación, y hasta hemos construido un campo disciplinario nuevo, la manualística.

En su versión impresa, un libro escolar es fácilmente identificable por las siguientes características:

- El formato. La estructura, tamaño y modelo material del libro escolar resulta inconfundible. Sus signos externos evidencian que se trata de un producto impreso destinado a sujetos escolarizados, es decir, un texto con identidad propia.

- La cubierta. Esta es la puerta de acceso al manual, una especie de cartel que reclamo con tipografías, formas y colores que estimulan la sensibilidad de destinatarios, niños y jóvenes. Es también en parte un poster motivante de lo que el libro encierra en su interior, dotado de una peculiar estética y de otros recursos simbólicos y comunicativos.

- La maqueta de las páginas interiores (mise en page). Su organización, la distribución del espacio gráfico, el uso de recursos para orientar una lectura de estudio y otros elementos de la maqueta textual revelan que su diseño está orientado como guía del proceso de aprendizaje y de enseñanza. Esta característica atribuye identidad al libro escolar.

- Las estrategias ilustrativas que utiliza como retórica iconográfica asociada a la escritura. La textualidad del manual suele ser una mezcla de imágenes y palabras, armonizada siguiendo estrategias informacionales, estéticas y didácticas que intervienen en la comunicación de los contenidos e incluso en la activación de actitudes.

- El implicit reader que subyace bajo su textualidad. Todo libro destinado a la enseñanza comporta un lector in fabula, un determinado sujeto que se presupone y que ha de comportarse conforme a un protocolo de acciones en parte predeterminadas, con algún grado de indeterminación. Este lector implícito es propio del manual y diferente de los lectores de otras textualidades. 
En su versión digital, las escrituras que circulan en Internet o en e-book, contingentes e indeterminadas, mimetizan a veces la geometría de los textos didácticos convencionales, y los sujetos lectores y escribanos también se sirven de ciertos patterns que organizan y dan sentido a los procesos de apropiación de los contenidos que se vehiculan en estos soportes. En este sentido, se puede afirmar que el texto digital es adaptado en parte, al ser manipulado, a la lógica del texto impreso, influida en este caso por la cultura escolar.

Es verdad que, como hizo notar Pierre Lévy (1999), el hipertexto está en continua metamorfosis, crea nodos y enlaces con elementos heterogéneos, genera modelos reticulares que son en parte fractales textuales y funciona siguiendo una dinámica policéntrica. Pero también es cierto que los sujetos, al construir el texto en procesos intraescolares, introducen en la textualidad resultante una cierta geometría que guarda relación con su habitus cognitivo, adquirido sobre todo en la experiencia escolar. La cultura de la escuela es pues determinante en la gobernabilidad de la contingencia de los textos que circulan en red. $Y$ de este modo, el texto resultante, que al mostrarse en interface o imprimirse se traduce en arquitectura influida por el estereotipo del manual, refleja rasgos del libro impreso convencional.

Puede afirmarse, pues, que la subjetividad del lector transforma el hipertexto, con grados de libertad, en una forma de textualidad reconfigurada desde los patterns de la cultura que promueve la escuela, esto es, desde las escrituras prácticas de la manualística. Cuando los bits de la red no se acomodan a estas pautas, y el navegante circula libremente, la textualidad se dilata y hasta logra producir cosidos o pliegues en el espacio digital, efectos virtuales de tercera dimensión, pero las estructuras mentales de los lectores que se apropian de las lexias terminan geometrizando el material inorgánico del hipertexto según reglas en parte modeladas por los hábitos que la escuela transmite.

\section{El manual: icono generacional y símbolo nacional}

El manual escolar tradicional se identifica como constructo textual acomodado a ciertos requerimientos sociológicos. Es un texto que puede ser condicionado políticamente, en la medida en que no puede salirse de los límites de contenido y valor que los gobiernos le marcan. Como dispositivo de normalización cultural de cada grupo de edad, el libro escolar es un exponente de un determinado código sociológico, si se quiere una representación de los estándares que la comunidad pauta para los sujetos escolarizados en una época. 
Además, al igual que los otros libros que circulan en el mercado, el manual escolar es un producto cultural intervenido. Primero, en función de las intenciones "culturales" de los autores que lo crean -considerando esta categoría en su sentido más general, y no sólo en su dimensión personal-. También por los sistemas de control que regulan la denominada "policía" del libro. Y en último término, por los criterios "culturales" de quienes lo seleccionan y usan como texto.

En el caso del libro electrónico, las intenciones pueden tener menos visibilidad, pero siempre subyacen bajo los intereses de quienes interactúan en la pragmática comunicativa y en los actores de la sociedad de la información, además obviamente de en las motivaciones de quienes utilizan el conocimiento que los textos vehiculan.

En otro orden de cosas, la construcción de la identidad de un manual está socialmente condicionada por dos factores. Uno se refiere al carácter de icono generacional que el libro escolar llega a tener. Cada generación se identifica, en este sentido, por los manuales que sus miembros han compartido como pares sociológicos de una cohorte escolar. Las escrituras e imágenes de estos textos han entrado a formar parte del imaginario social de una generación y de la identidad narrativa de los sujetos que pertenecen a ella. El otro condicionamiento sociocultural se asocia a la función atribuida al libro escolar como símbolo de una cultura nacional, de un conjunto de conocimientos y valores que constituyen la tradición disponible transmitida a un grupo.

Alain Choppin (1993), uno de los iniciadores de la manualística en Europa, ha querido ver en el manual escolar un símbolo de la identidad cultural de las naciones, por cuanto a través de él las sociedades habrían tratado de perpetuar y sellar sus características, sus valores, sus tradiciones. Como la moneda o el timbre postal, el libro de enseñanza, sujeto a controles del sistema desde los orígenes del Estado liberal del XIX, es una producción nacional vigilada que no sólo vehicula la lengua oficial de un país, sino los símbolos y los valores patrios que constituyen las bases de la sociabilidad de los menores del tejido social, los códigos de la cohesión identitaria de una nación. De ahí la lucha de los grupos que quieren afirmarse como culturas nacionales por asegurarse el control de los libros de uso en la escuela pública.

El hipertexto está cambiando la función que el texto tradicional cumplía como instrumento transmisor de los códigos de sociabilidad. Los contenidos de las lexias pueden comportar valores y esquemas cognitivos, entre otras cosas porque los medios y sus formas implican por sí mismos mensajes y expresan por tanto patrones de cultura. Pero esto no es igual a lo que ocurría con los textos anteriores. El 
ethos de los manuales clásicos constituyó un discurso cohesionado, jerarquizado en torno a reglas de verdad definidas a priori por la intelligentsia que dotaba de gobernabilidad al sistema. Sin embargo, los valores en el medio digital son una construcción de sentido que los sujetos van elaborando en la misma interactividad y conectividad, dos atributos que formalmente parecen estar mejor dotados para la democracia cultural, y hasta para ser el antídoto de dogmatismos, salvo que se sospeche que, bajo su inocente sincretismo, subyazca la lógica de los poderes visibles y no visibles de la sociedad-red.

En todo caso, sí parece evidente que la disolución del texto directivo resulta coherente con la crisis discursiva de la posmodernidad, en la que los grandes relatos han perdido legitimidad y en la que el supremo valor reside en la performatividad que regula la interacción comunicativa e instrumental de los actores en la red. Y como los nuevos ecosistemas comunicativos no sólo transforman la narratividad (los actos narrativos) sino la narración resultante, parece plausible que esas mismas reglas de la retórica mediática se erijan en relato y valor, esto es, en el ethos de la hermenéutica hipertextual.

\section{Interacciones y sincretismos en la era digital}

Pese a la plausible veracidad de las observaciones anteriores, algo más podría estar ocurriendo hoy en la interacción texto-hipertexto o manual-red-multimedialidad. Si se observan con atención las tramas textuales de los manuales de la última generación, no es difícil percibir que, además de comportar su utilización un lector implícito más versátil y errático -análogo en parte, al menos en la intención y en algunas formas, al lector navegador de las nuevas mediaciones-, su estructura comporta una yuxtaposición de textos e imágenes, de arquitectura no bien jerarquizada, que permite diversos procesos, itinerarios y lecturas, una disposición bien distinta a la organización de la información que ofrecían los libros de la escuela tradicional, y aún de la moderna, más rígida y dogmática, y por consiguiente más formalmente programada.

Ciertas pautas están cambiando en la retórica que subyace en estos textos, en las relaciones que se establecen entre la escritura y la acción implícita en su pragmática comunicativa, en los modos de interacción entre la palabra y la iconografía, y en las implicaciones entre la base del texto y otros textos externos a los que se reclama; en definitiva, entre la logística del autor y el comportamiento del lector implícito. Algunos cambios de los sugeridos proceden de las innovaciones del libro activo, y tienen 
por tanto ya una cierta tradición, pero otros pueden interpretarse como transferencias o mimetizaciones sincréticas-metamorfosis tal vez-que la última manualística hace de los patrones comunicativos creados por las estructuras y lenguajes on-line.

Los bloques en que se articulan las páginas de estos libros no son lexias unidas por enlaces electrónicos o links, pero sí invitan a comportamientos nómadas y hasta adoptan formas de rizoma, como en la semiología que describió hace tiempo Gilles Deleuze (1988). Si fuera así, la nueva textualidad didáctica vendría a constituirse, para poder sobrevivir, en respuesta a las críticas de los viejos impresos y las formas cognitivas dogmáticas, y tal vez incluso en una metáfora del constructivismo ecléctico democratizador de la cultura. La linealidad de la pragmática tradicional desaparece y el laberinto hace una sutil presencia para invitar a la construcción personalizada, narrativa por tanto, del saber, del currículum y de la propia textualidad. Tal narratividad aboca a una hermenéutica interactiva, intersubjetiva, de los contenidos transmitidos y de los lenguajes en que se expresan, que es la vía más compatible con la intertextualidad resultante y con las formas intermodales de comunicación. Bajo estas respuestas adaptativas sincréticas, el manual se renueva pero también sobrevive como invariante pedagógica en la cultura de la enseñanza.

El manual, modernizado, pervive pues en la práctica escolar, y aún prolifera y se afirma, pero el giro digital -que no ha hecho más que comenzar- propone nuevas textualidades. ¿Cómo conviven, cohabitan, e interaccionan texto y red? Querámoslo o no, escribía Michael Appel (1989) hace algunos años en Maestros y textos, las dos terceras partes de lo que hacían los enseñantes y los alumnos en el interior de las aulas de las escuelas de nuestro tiempo tenían que ver, de una u otra forma, con los libros. Esto ha cambiado hoy, pero sigue siendo verdad que el manual persiste en la escuela actual como mediación pedagógica esencial. En otro contexto, Umberto Eco, saliendo al paso de las nuevas apologías del imperio de la red, reafirmaba el valor del libro como instrumento princeps en la transmisión del saber, esto es, como mediación pedagógica en la sociedad del conocimiento (“¿Qué se haría hoy en una clase en un día de black out?”-se pregunta el conocido semiólogo de Bologna) (Eco, 2004, p.4).

Es verdad, sin duda, que la nueva sociedad multimedial y del conocimiento está suscitando una dialéctica de sustituciones y un nuevo juego crítico entre apologistas e integrados de los nuevos medios, así como la producción de ciertas formas intermodales de comunicación que afectan a las mediaciones pedagógicas clásicas y que dan entrada a otras modalidades textuales, sincréticas muchas veces. En cierto modo, el 
hipertexto, al ser manipulado, no logra liberarse de la episteme geométrica que introduce un determinado orden en la aparente contingencia, lo que implica modos de lectura transferidos a las nuevas escrituras desde la lógica cognitiva adscrita al habitus de los usuarios educados en el manejo de textualidades formalizadas. Es evidente, pues, que, como advirtió Pierre Lévy (1999), los modos de escritura se muestran hoy también de manera superpuesta unos con otros y que no se sustituyen unos a otros. La sucesión oralidad-escritura-hipertexto no respondería por tanto a una dinámica de sustituciones, sino a un proceso de complejización sincrética de la lingüisticidad, que puede implicar incluso el retorno de algunas formas de oralidad. Esta conclusión, que tendría incluso un alcance ontológico en los círculos hermenéuticos que asocian memoria y lenguaje, posee implicaciones histórico-culturales y pedagógicas.

Como ya advirtió Roger Chartier (2006), las revoluciones de la cultura escrita nunca han producido sustituciones o cambios radicales. El manuscrito sobrevivió en la época de la tipografía impresa, y el libro de imprenta también cohabita hoy con el hipertexto en pantalla. Más aún, las escrituras contemporáneas, además de apropiarse de tradiciones bien establecidas y de producir modos sincréticos de expresión, generan a menudo modelos intertextuales que no siempre son innovadores. El propio Eco viene a concluir en el trabajo citado que Internet no está destinado a sustituir a los libros, como parecen suponer los más simplistas e ingenuos sociólogos, sino que puede llegar a ser un buen complemento e incentivo para leer más. Desde esta perspectiva, el libro de texto podría seguir siendo el master o magister que selecciona información y orienta la búsqueda de otras informaciones, función que no pueden cubrir por sí mismas las redes fragmentarias y caóticas del ciberespacio. Además, la práctica de la navegación en redes, como ha mostrado Martin E. Rosenberg (2004), termina por adaptar la estructura no lineal y contingente de los textos a una cierta arquitectura de la sucesión, que resulta compatible con la retórica clásica del uso del impreso, con lo que las nuevas formas de comunicación incorporarían correlativamente algunas características de la textualidad del manual convencional. De una u otra forma, el libro escolar, impreso o digital, sigue siendo un texto ordenado a la comunicación conforme a ciertas reglas que son estructuradas y estructurantes.

El manual que sobrevive en entornos abiertos a la nueva escritura puede además enseñar a descubrir, en otras fuentes convencionales, o en la propia red, aquello que el profesor está olvidando, y hasta constituirse en archivo del canon de la memoria del conocimiento escolar, marco de referencia necesario. Internet -añade Umberto Eco- 
podría, a este respecto, sustituir a los diccionarios y a las enciclopedias del saber, que son los materiales que más pesan en las mochilas de los escolares, pero no guiar la necesaria selección cultural que ordena las mentes y organiza las estructuras cognitivas.

No obstante lo anterior, resulta evidente que las características tradicionales y modernas del texto didáctico se han transformado en los medios y entornos telemáticos en que se sustenta la revolución digital de nuestro tiempo, y que estos cambios han modificado no sólo los soportes y lenguajes de la escritura, sino la misma ecología de la comunicación y el papel que desempeñan los actores que intervienen en la producción y recepción de los mensajes. Hay ciertamente en los nuevos ecosistemas montajes y complicidades que se fusionan en distintos juegos de lenguaje, también sincréticos, formas orales, escritas y multimediales de la pragmática comunicativa.

Veamos cómo está afectando el mundo de la red, sus tecnologías y su misma lingüisticidad, a las nuevas formas de construcción de la cultura de la escuela y del texto. La red ya no es, como lo era el manual impreso, el soporte de un currículum canónico, secuencializado y jerarquizado, sino el medio sin centro en el que circulan un número indeterminado de lexias, un río cuya orilla se estructura y cambia con el caudal de bits informacionales que se introducen en él o que son traídos mediante prácticas de conectividad a la presencialidad de la pantalla (interface) para ser utilizados. El sujeto lector implícito ha sido definido con la metáfora del navegante que interactúa con este material caótico y que estructura desde sus demandas específicas el orden cultural, y además resignifica (vuelve a escribir al leer, en el sentido derridiano) todo lo que lee y escribe. El libro escolar clásico no disponía de estos grados de libertad, ya que la diferenciación en él entre el lector y el autor es sólo estratégica. En definitiva, la guía didáctica del enseñante es un texto directivo (o paratexto) que controla en el fondo todo el proceso. El hipertexto libera en cambio a los sujetos de las reglas académicas a que estaba sometido el texto convencional. El nuevo modelo retorna, en cierto modo, al sentido originario de todo texto, que promueve la acción de trenzar o entretejer (textere), y se configura mediante los enlaces que generan intertextualidad. En este sentido el hipertexto es, si cabe, aún más texto.

El currículum que transmite aquí la red es por tanto abierto, sin autor, aunque sí con un lector múltiple capaz de producir al leer continuas reescrituras, opciones de una virtual gramatología de la diferencia. Bajo estos autoprogramas subyace un discurso antrópico que invita a la construcción narrativa y hermenéutica del currículo. 
La desaparición del autor, o de su visibilidad, presupone la existencia de una autoría colectiva. Esta lógica es compatible con la de la posmodernidad, donde el texto se independiza del autor y es el lector quien construye, desde sus preguntas y con los fragmentos encontrados en las búsquedas orientadas o en los encuentros contingentes y aleatorios con materiales no previstos, su propio texto, y crea al tiempo nuevos significados. Todo parece orientarse pues hacia un nuevo constructivismo de complejas y no siempre previsibles consecuencias epistémicas y disciplinarias.

Las mutaciones anteriores amenazan con transformar el texto curricular en un caos con infinitas hipotaxis que carecen en principio de una cohesión holista. Bajo esta presión, el discurso hipertextual no puede dejar de ser iconoclasta respecto al rígido orden del currículum convencional, pudiendo verse abocado a la dinámica de los textos expuestos en forma de laberinto, entre los cuales el lector se podría sentir extraviado, perdido (lost in hyperspace) (Gaggi, 1997). En esta nueva mediación, como en la circulación nómada, errática u orientada, por los laberintos de la red, cada performance es una especie de producción original o de intuición de una revelación que nunca se alcanza, como ocurre con la creación estética. Frente a la página en blanco, el laberinto es seguramente la primera creación del arte infantil que, como señaló agudamente Jacques Attali, imitan después el arquitecto, el urbanista, el pintor, el coreógrafo o el diseñador de redes (Attali, 1996; Landow, 1997).

El método y el proceso de la alfabetización digital y las formas de navegación online han cambiado el modo de producción del currículum y los métodos empleados en su puesta en escena. El viejo texto impreso fijaba el conocimiento a leer, a aprender o a reproducir por mímesis. En el hipertexto, el principio, el fin y el proceso no están predeterminados. Ya el género de libro activo inventó un sujeto móvil y una relación dinámica entre texto y lector. Pero la nueva interface impone otros comportamientos y otros métodos, radicalmente distintos, y hasta incluye a los lectores, asimilándolos en su mismo medio como contenido y eludiendo incluso su condición de sujetos.

Al entrar en la comunicación on-line, la relación de los lectores con los textos alcanza grados de versatilidad que generan cambios cognitivos aún no bien conocidos pero importantes y, ya sea en su dimensión personal, o mejor aún, en la que ofrecen las comunidades virtuales, aboca a nuevas síntesis sistémicas y ecológicas. La nueva revolución de la escritura va a afectar, además, no sólo a las mediaciones didácticas, sino a toda la ecología de las aulas y de sus entornos, y ello va a generar una transformación en los métodos, aunque el libro pueda sobrevivir. 


\section{El libro escolar y la cultura de la escuela}

En las últimas décadas, el manual ha llegado a ser considerado, bajo el influjo de las orientaciones etnográficas y hermenéuticas, una fuente esencial para aproximarse a la "gramática de la escolarización" (Escolano, 2006a). El libro es visto así como uno de los más visibles sintetizadores de la cultura empírica de la escuela. En él se puede examinar el curriculum editado de cada época. Es un espejo de la sociedad que lo produce y en la que circula, en el que se reflejan los valores dominantes, los estereotipos y las ideologías de la sociedad. Bajo sus estructuras subyace asimismo el método (la ratio), la estrategia de gestión del programa, las reglas de la profesión docente (el habitus del oficio de enseñante) y el perfil del implied reader que ha de usarlo. ¿No son estos los códigos de la "gramática escolar" que tratamos de descodificar?

La cultura de la escuela se ha constituido en un objeto esencial para la nueva historiografía de la educación. Entendida, tal como la definió Dominique Julia (1995) en la década de los noventa, como el conjunto de normas que definen los saberes y las conductas que la escuela transmite y la serie de prácticas que las instituciones han construido para la transmisión de las disciplinas y la inculcación de comportamientos, la cultura de la escuela desvelaría los "silencios" de la historia de que habló Harold Silver (1992), las claves con que abrir la "caja negra” del cotidiano escolar (Depaepe; Simon, 1995), cuyo revelado es necesario para el conocimiento de las reglas implícitas en la "gramática de la escolarización" (Tyack; Cuban, 2000).

Pues bien, en este orden de cosas, el manual escolar, como registro de toda la cultura escolar, es una fuente importante, decisiva, para afrontar esta estrategia de conocimiento. El libro puede ser examinado como una representación de las prácticas que prevé e induce, como un soporte en el que subyacen los discursos pedagógicos acerca de la acción escolar y como un objeto indiciario de los valores en que se fundamenta la administración que lo regula. Esta revalorización del libro escolar como fuente ha dado origen a la creación de un nuevo campo intelectual no sólo historiográfico, teórico y pragmático: el que se cubre bajo el término manualística.

Desde la perspectiva de la cultura empírica, el manual es un objeto-huella portador de signos indiciarios de la conceptualización y la pragmática de la enseñanza. Su análisis lingüístico, semiológico e iconográfico puede aproximarnos al conocimiento de los códigos que dan identidad a una determinada pedagogía. Bajo la perspectiva de la cultura teórica, el libro es un texto discursivo que comporta conceptualizaciones implícitas y tradiciones de sentido. En las prácticas discursivas que se expresan me- 
diante los lenguajes, las retóricas y los recursos comunicativos se pueden leer valores culturales y teorías didácticas. En el orden de la cultura política, un texto es el exponente legible de las intenciones de los actores que intervienen, del marco normativo que regula la sociabilidad educativa y de los valores que regulan las relaciones entre los miembros de una comunidad hermenéutica.

En resumen, el libro escolar es una mediación con señas propias de identidad por su geometría textual y por los atributos culturales que le confiere la sociedad. Como representación holística de toda la cultura de la enseñanza, el manual-un objeto hasta hace poco excluido de los bienes culturales- se ha constituido hoy en una fuente esencial para desvelar algunas claves de la "caja negra" de la gramática de la escuela.

Por todas las consideraciones anteriores, el manual de enseñanza ha sido y sigue siendo una especie de invariante de la cultura de la escuela. A comienzos del último siglo, el movimiento de la llamada Escuela Nueva, que se autodefinió como un movimiento antilibresco, y que pivotó sobre la afirmación de los principios de la intuición y de la acción, frente a la larga y sostenida tradición verbalista de la enseñanza, terminó por integrar estos postulados en un nuevo paradigma que también asumió los soportes textuales. De una parte, esta corriente innovadora inventó nuevas composiciones que respondían al género de libro activo, un modelo que implicaba un nuevo sujeto lector y que traducía en soportes impresos los principios de una enseñanza centrada en el alumno y de la metodología intuitiva. De otro lado, el activismo introdujo modificaciones en los manuales que estaban en circulación en la práctica escolar. Las lecciones de cosas, los centros de interés, las concentraciones y los proyectos, por citar los patrones más conocidos, constituyen un buen ejemplo de los procesos de asimilación-apropiación que hacen los textos de los supuestos teóricos y prácticos de un cambio de paradigma pedagógico como era el que auspiciaba la escuela renovada.

En el trabajo sobre la cuestión que presentamos en el congreso de la ISCHE de 2004 (Escolano, 2006b) mostramos cómo la gramática interna de la escuela, los códigos de la cultura empírica de la educación, el mismo habitus del oficio de enseñante, y las prácticas dominantes entre los autores de textos y en el sector editorial, condicionaron la traducción de los principios de la Nueva Educación al mundo de la realidad, al mismo tiempo que las propuestas de renovación también modificaban la tradición manualística vigente. En estos procesos de cambio histórico, una cierta negociación, no siempre bien explicitada, producirá resultados eclécticos que permitirán, de una parte, sobrevivir al texto como invariante didáctica, así como a su cultura 
subyacente, al mismo tiempo que renovar las prácticas pedagógicas arcaizantes con la incorporación, bajo determinados supuestos, de las innovaciones emergentes en la vanguardia de la educación.

Por su prolongada y universal existencia, bajo diferentes formas, en las instituciones de todos los tiempos y de todas las culturas, por la resistencia que ofrece a desaparecer de las prácticas dominantes en la vida de los establecimientos, y hasta por las sucesivas acomodaciones a los cambios mediáticos y comunicativos que se operan en el exterior de la escuela, el libro se ha constituido en un medio representativo, real y simbólico, de los modos de concebir y practicar la educación formal. Y en la actualidad, el manual, sin perder su identidad textual, está acomodándose, como hemos visto, a los cambios que se suscitan en los soportes y lenguajes bajo el impacto del giro digital.

Todo texto didáctico, como micromundo, es en primer lugar un soporte curricular, es decir, una forma de materialización del llamado currículum editado, que no es todo el programa escolar ciertamente, pero sí la versión impresa de la vulgata en que se traduce el currículo normativo y la propuesta de conocimientos y acciones que suele orientar la práctica de la enseñanza en un gran número de escuelas y en una buena parte de los comportamientos etnográficamente constatables entre los enseñantes.

Un manual es asimismo un espejo de la sociedad que lo produce, en la medida que sus contenidos, lenguaje e iconografía plasman los valores, estereotipos e ideologías que definen a la mentalidad establecida, tal como ésta es interpretada por los autores que lo escriben y los filtros de la policía del libro que lo aprueban, es decir, de los círculos y actores que lo producen y legitiman. Incluso, podría añadirse, de las expectativas de sus usuarios, en la medida en que estos lectores están también implícitos, toda vez que han sido previstos en la escritura de los textos. Textos e imágenes son una fiel representación de los códigos de sociabilidad vigentes en cada tiempo y lugar, epitomizados en clisés de fácil memorización, como conviene a los tradicionales modos de enseñanza basados en la mímesis o reproducción de modelos.

El libro escolar es finalmente una ratio, el libretto que guía el desarrollo de la actividad, una parte esencial del método que pauta buena parte del proceso de la enseñanza. Todo libro es por tanto una representación de los modos de comunicación didáctica y de las estrategias que marcan el gobierno de las aulas. Sin partitura no es posible ni la representación de la acción ni la acción misma. Un texto puede ser, en este sentido, un elemento regulador de lo que en el pasado se llamó la "marcha 
de la clase” y hoy se denomina, con el lenguaje tecnocrático de la época, la gestión del currículum. A comienzos del XIX, el manual, en España, era propiedad de la escuela o del docente. No era frecuente que un escolar pudiera disponer del texto. Después, a medida que la enseñanza simultánea se difundió, y se transformó por tanto la mise en scène de la clase, la partitura pasó a manos de los alumnos. En la enseñanza simultánea, colectiva o seccionada, el libro se hizo imprescindible para asegurar la misma coreografía o escenografía de la escuela, esto es, para armonizar el clima de trabajo de las aulas.

El libro sigue conservando en nuestro tiempo los atributos que le dieron identidad. Su formato y el lector implícito adoptan modelos inspirados en los patrones digitales, que combinan sincréticamente con los clásicos, pero mantienen pautas estructurales. Se moderniza el diseño de la mise en scène de sus maquetas, las estrategias ilustrativas -influidas por lo multimedial- el modus typographicus de su escritura y otros elementos de su composición, pero conserva la lógica de la cultura impresa. El libro sigue siendo el eje de numerosas relaciones -tal como lo concebía Jorge Luis Borges hace más de medio siglo-, y no sólo una estructura verbalizada.

En definitiva, todo texto, el clásico y el digital, bajo una u otra materialidad, en uno u otro soporte, es lo que sus lectores hacen con él en la práctica. Ningún texto existe fuera de la materialidad en que se inscribe (Chartier, 2006), pero tampoco sin los procesos de apropiación que hacen los sujetos al interaccionar con las formas y contenidos de la cultura gráfica que en él se manifiesta. Estas apropiaciones, que son lecturas, o reescrituras, son las que determinan la construcción y la coautoría del texto.

\section{La manualística como campo intelectual}

En poco más de una década, el libro escolar se ha constituido en una fuente esencial para el conocimiento de los códigos que definen el mundo de la educación en sus dimensiones prácticas, discursivas y sociopolíticas, al mismo tiempo que en un objeto de interés generalizado para la inteligencia y comprensión de los modos de sociabilidad cultural que han conformado en el pasado, y que estructuran en el tiempo presente, las mentalidades individuales y colectivas en las comunidades letradas.

No sólo la ciencia y la pragmática de la educación, sino la historiografía de la escuela, tras el giro iniciado en los últimos años por ésta hacia los enfoques etnográficos y hermenéuticos, que se orientan fundamentalmente a la descodificación de las claves de memoria implícitas en los llamados objetos-huella de la cultura de la 
enseñanza -de los que el manual, como se ha dicho, es uno de los más universales-, han puesto asimismo en valor estos viejos útiles de la escuela tradicional y moderna, abandonados hasta hace poco tiempo a la destrucción o el olvido. Ello está comportando una cierta reificación material del archivo histórico de la educación que incluye como fuentes a los textos.

Como consecuencia de todo lo anterior, la convergencia de expectativas entre los teóricos, los historiadores y los prácticos ha dado origen a un nuevo campo intelectual en el mundo de la investigación educativa que nosotros mismos nos aventuramos en atribuirle el nombre de manualística, sector disciplinario, emergente hace unos años pero ya consolidado, que acogería al conjunto de desarrollos discursivos, análisis genealógicos y observaciones empíricas que se han ido configurando en torno al libro escolar como objeto de conocimiento (Escolano, 1997). Este ámbito de estudios ha producido ya en las últimas décadas un amplio y diversificado elenco de trabajos, ha configurado grupos estables de investigación en las universidades, y ha suscitado la aparición de redes museológicas y documentales en las que se objetiva la memoria material en que se sustenta la tradición del sector y la trama de relaciones que sirve de soporte académico al nuevo campo de conocimiento.

Esta línea de investigación afecta asimismo a la conceptualización del manual como constructo textual específico, dotado - pese a las metamorfosis que sufren las escrituras en la versión digital al transportarse a otros soportes y lenguajes - de reglas de producción que son estructurantes, es decir, que poseen señas de identidad. La manualística ha emergido como ámbito de investigación educativa en paralelo con los cambios mediáticos que se han generado en torno al giro digital que venimos glosando, pero polarizándose en la reconstrucción de la memoria del libro, es decir, en la investigación de los atributos materiales y formales del manual como texto.

Este es un indicador más de la complejidad que caracteriza el nuevo espacio de trabajo, a la que se refiere John Issit (2004). Cabe incluso preguntarse -ipor qué no?si la afirmación de este nuevo campo intelectual, además de estar conectada con las corrientes etnohistóricas que hoy dominan en los estudios sobre la cultura de la escuela, no es al tiempo una llamada de atención, tal vez no exenta de ciertos resabios academicistas, sobre los riesgos a que puede verse sometida la invariante pedagógica en que se constituyó la tradición textual, y hasta un intento de reacción de supervivencia y legitimación del codex frente a las tecnologías que amenazan sustituirle.

Hasta no hace mucho, los manuales escolares, y otros materiales de uso en la en- 
señanza, habían quedado adscritos al mundo de los objetos excluidos de los bienes culturales por la episteme idealista y positivista que ha informado en el pasado a las ciencias humanas. Estos modos de construcción intelectual rompieron en realidad con la memoria y desestimaron todos los testimonios de la cultura material, a los que consideraron ingenuos restos arqueológicos, interesantes tal vez para curiosos coleccionistas de fetiches, pero banales en cuanto a su potencial poder explicativo. En este contexto sólo una genealogía de la sospecha podía entrever el valor simbólico-representativo y empírico-práctico que tan inocentes instrumentos podrían tener para explicitar claves con las que entender el origen de ciertas prácticas y de la semántica del sistema. Y así comenzó justamente el interés académico y social por la manualística.

Construir un campo es definir en parte también un nuevo texto y unas nuevas interacciones o jugadas entre los actores que intervienen en la cultura escolar y en su interpretación. Ello implica asimismo, además de dotar de visibilidad a nuevos indicadores culturales, desmitificar el archivo anterior, animar a decodificarlo, ponerlo en confrontación con otras fuentes de conocimiento y sabiduría. La deconstrucción a que nos invita esta epistemología crítica es una especie de operación estratégica que introduce un desorden propedéutico, instrumental, para desvelar los códigos implícitos en la cultura de los bienes excluidos, que se supone son los que operan en los comportamientos reales de los sujetos y en las estructuras implícitas de las instituciones.

Desde los anteriores planteamientos, el nuevo campo disciplinario de la manualística debe construirse atendiendo a las contribuciones de la genealogía de los discursos y de las experiencias relacionadas con las mediaciones pedagógicas, así como a los aportes de las investigaciones relativas a la pragmática de la educación, incluidas todas las perspectivas teóricas, semiológicas, antropológico-culturales y didácticas.

La configuración de este ámbito ha estado dominada por la lógica de la historiografía, lo que se explica en parte por haberse gestado el campo en un contexto académico influido por el giro micro y etnohistórico que han adoptado últimamente los reconstruccionismos genéticos de las prácticas socioculturales -que no afectan sólo al mundo de la educación, sino a la mayor parte de las esferas de la cultura-. Pero esta historización de origen que ha tenido el tema tiende ya a ser trascendida, de suerte que el campo intelectual de la manualística se está abriendo a todas las disciplinas que tienen que ver con las dimensiones discursivas y factuales de la cultura de la escuela y con las que analizan los contextos en los que los libros se escriben y en los que circulan. 
La manualística es hoy en día un campo en construcción, un ámbito muy abierto, en el que la introducción de nuevos temas y enfoques (como los derivados del giro digital comentado) puede romper las reglas del juego intelectual. Las textualidades en red, en el caso referido, pueden cambiar los esquemas perceptivos, las orientaciones de sentido y los consensos de significación, las relaciones internas y externas entre actores, los dispositivos metodológicos e incluso toda la ecología del sistema pedagógico. Ello comportará una reconceptualización del campo establecido y también un nuevo formateado del territorio intelectual y operativo en el que trabajar. La teoría del campo, en su concepción más dinámica, puede asumir la anterior inestabilidad, así como las prácticas de resignificación que implican los giros discursivos deconstruccionistas o constructivistas derivados de las estrategias comentadas. Ésta es, en definitiva, la mayor garantía para un modelo abierto que contribuirá a redefinir la identidad del texto escolar.

\section{Referências bibliográficas}

APPLE, Michael W. Maestros y textos (Teachers and texts). Barcelona: Paidós, 1989. ATTALI, J. Chemins de sagesse: traité du labyrinth. Paris: Fayard, 1996.

CHARTIER, Roger. ¿Qué es un texto? In: CHARTIER, Roger. ¿Qué es un texto? Madrid: Círculo de Bellas Artes, 2006.

CHOPPIN, Alain. Manuels scolaires, États et sociétés, XIXe-XXe siècles: introduction. Históire de l'Éducation, n. 58, Paris, França, mai 1993, p.5-7.

DELEUZE, Gilles. Diferencia y repetición. Madrid: Júcar, 1988.

DEPAEPE, Marc; SIMON, Frank. Is there any place for the history of education in the History of Education? Paedagogica Historica, Gent, XXX-1, 1995.

ECO, Umberto. El libro escolar como maestro. España: El Mundo, p. 4, 2004.

ESCOLANO, Agustín (dir.). Historia ilustrada del libro escolar en España. Madrid: Fundación G.S. Ruipérez, 2 v., 1997-1998.

ESCOLANO, Agustín. Currículum editado y sociedad del conocimiento: texto, multimedialidad y cultura de la escuela. Valencia: Tirant lo Blanch, 2006a. 
ESCOLANO, Agustín. La recepción de los modelos de la Escuela Nueva en la manualística escolar española de comienzos del siglo XX. Historia de la Educación, Salamanca, 25, p. 317-340, 2006b.

GAGGI, Sergio. From text to hypertext: decentering the subjetc in fiction. Philadelphia University Press, 1997.

ISSIT, John. Reflections on the study of textbooks. History of Education, v. 33-6, p. 683-696, 2004.

JULIA, Dominique. La culture scolaire comme objet historique. In: NOVOA, A. (ed.). The Colonial Experience in Education. Paedagogica Historica, Gent, Supl. Series. p.356, 1995.

LANDOW, George. Teoría del hipertexto. Barcelona: Paidós, 1997.

LÉVY, Pierre. ¿Qué es lo virtual? Barcelona: Paidós, 1999.

ROSENBERG, Martin. Contingency, liberation and seduction of geometry: hypertext as an avant-garde medium. Open Forum, "El relato digital", 2004.

SILVER, Harold. Knowing and not knowing in the History of Education. History of Education, n. 21-1, p. 97-108, 1992.

TYACK, David; CUBAN, Larry. En busca de la utopia. México, FCE, 2000.

Recebido em 29 de março de 2012 e aprovado em 11 de maio de 2012. 